\title{
QUALITY DIFFERENCES ASSESSMENT IN CANNED SARDINE (Sardina pilchardus) BY FLUORESCENCE DETECTION
}

\section{S. Aubourg* and I. Medina}

Instituto de Investigaciones Marinas (CSIC)

c/ E. Cabello, 6

36208-VIGO (Spain)

Phone: +34-86-231930

Fax: +34-86-292762

E-mail: saubourg@iim.csic.es 


\begin{abstract}
Chilled (0, 2, 6, 10, 13 and 15 days) and frozen (0, 0.5, 2, 4, 8 and 12 months) sardines were used to determine the influence of such storage times of fish over the quality of the final canned product. Traditional determinations of lipid quality (free fatty acids content, thiobarbituric acid index and polyene index) were studied and compared with the formation of fluorescent compounds expressed as the ratio between fluorescence readings taken at two excitation/emission maxima (393/463 nm and $327 / 415 \mathrm{~nm})$. No clear correlations were found between the common measurements of lipid deterioration and the time of storage prior to canning. Satisfactory correlations were found between the fluorescence ratio obtained from the filling medium of cans and the time of storage of the starting material $(r=0.90$ and $r=0.91$ in brine and oil canned samples, respectively). According to the present results, fluorescence detection of interaction compounds can provide a rapid and sensible method to assess quality differences in the final product as it relates to the quality of the raw material used.
\end{abstract}

Running title: Quality determination of canned sardine by fluorescence Keywords: Canning, fluorescence, lipid deterioration, quality, sardine. 


\section{INTRODUCTION}

Canned fish and other processed marine species are products of great economic importance in several countries. The majority of quality problems found in canned products can be related to the quality of raw material, which continuously changes during storage which can include freezing and chilling (Cheftel and Cheftel, 1976; Pigott and Tucker, 1987). Marine lipid composition is highly unsaturated (Ackman, 1989) and oxidation during storage and processing is likely to occur, leading to quality loss (Pearson et al., 1977; Ackman, 1988).

Many methods have been used to measure primary (peroxides) and secondary (carbonyl compounds) oxidation products as a degree determination of quality deterioration (Melton, 1983; Kim and Labella, 1987). However, most of these methods are difficult to use for quality assessment during heating since oxidation products are unstable and tend to react with compounds with free amine groups (proteins, peptides, free amino acids and some phospholipids) (Gardner, 1979; Leake and Karel, 1985). As a result of this kind of reactions, browning, flavor changes (Pearson et al., 1977; Pokorný, 1981) and loss of essential nutrients (Nielsen et al., 1985; Hidalgo et al., 1992) have been observed during processing.

The analysis of the compounds resulting from these interactions has been carried out by measuring the fluorescence formation at a single excitation/emission wavelength maximum (Bouzas et al., 1985; Lubis and Buckle, 1990; Maruf et al., 1990).

Previous work carried out on fish muscle after thermal treatment has found a bathochromic shift of fluorescence related to an increase of lipid oxidation depending on time and temperature of processing (Aubourg et al., 1992a, 1992b and 1995b). The 
fluorescence ratio between two of the maxima investigated (393/463 nm and 327/415 $\mathrm{nm}$ ) has shown to be correlated with quality during chilling (Aubourg et al., 1997).

In the present work the influence of the storage time of fish previous to canning was determined. Raw sardines were stored at two of the most common storage conditions (chilling: $0^{\circ} \mathrm{C}$, on ice; and freezing: $-18^{\circ} \mathrm{C}$ ) and then canned according to the typical process employed in canneries. Qualities of the resulting canned products were compared by means of the traditional lipid quality determinations (free fatty acids content, thiobarbituric acid index and polyene index) and fluorescence formation. The usefulness of the fluorescence detection was analyzed for two types of filling media (brine and oil) widely employed for canning and also on the organic and aqueous extracts resulting from the lipid extraction of sardine muscle.

\section{EXPERIMENTAL PROCEDURES}

\section{$\underline{\text { Raw material, chilled and frozen storages }}$}

Fresh sardines (Sardina pilchardus) were obtained in a local market (twelve hours after capture). Upon arrival at our laboratory, individual fish were stored in isothermal rooms at $0^{\circ} \mathrm{C}$ (on ice) and $-18^{\circ} \mathrm{C}$. Inside each temperature, sardines were randomly distributed into three groups that were studied independently. Chilled sardines from each batch were taken for canning after: 0, 2, 6, 10, 13 and 15 days of storage. Frozen sardines were taken for canning after: 0, 0.5, 2, 4, 8 and 12 months of storage.

\section{Canning process}

Chilled and frozen sardines were steam cooked in our pilot plant $\left(102-103^{\circ} \mathrm{C}\right)$ to a final backbone temperature of $65^{\circ} \mathrm{C}$ (Pérez-Martín, et al., 1989); the fish were then cooled at room temperature $\left(14^{\circ} \mathrm{C}\right)$ for about 3 hours, headed and eviscerated. 
Two individual sardines were placed in each small flat rectangular can (105 x 60 x $25 \mathrm{~mm}$; $150 \mathrm{ml})$. Two filling media were tested. For it, brine $(20 \mathrm{ml}$ of $2 \% \mathrm{NaCl}$ in water) was employed as filling liquid in cans containing sardines that had been kept chilled; olive oil (20 ml) and salt (2 g) were employed in cans containing sardine that had been kept frozen. Cans containing only oil were also prepared (canned oil blanks).

The cans were vacuum sealed and sterilized in a retort $\left(115^{\circ} \mathrm{C}, 45\right.$ minutes; $\mathrm{F}_{\mathrm{o}}=$ $7 \mathrm{~min}$ ). After 4 months of storage at room temperature, the cans were opened and the liquid (brine or oil) was carefully drained off. The white muscle of sardine and the filling medium were used for analysis.

\section{Basic analyses}

Water content was determined by weight difference of the homogenized muscle (1-2 g) before and after 24 hours at $105^{\circ} \mathrm{C}$; results are expressed as g water/100 g muscle. Lipids were extracted by the Bligh and Dyer (1959) method and quantification was carried out according to Herbes and Allen (1983). Results are expressed as g lipids /100 g muscle.

\section{$\underline{\text { Lipid damage measurements }}$}

Free fatty acids (FFA) content was determined by the Lowry and Tinsley (1976) method based on a complex formation with $\left(\mathrm{Ac}_{2} \mathrm{O}\right)_{2} \mathrm{Cu}$-pyridine. Results are expressed as g FFA/100 g lipids.

The thiobarbituric acid index (TBA-i) (mg malondialdehyde/Kg muscle) was determined according to Vyncke (1970).

Lipid extracts corresponding to brine canned samples were converted into fatty acid methyl esters and analyzed by Gas-Chromatography according to Lepage and Roy 
(1986). The polyene index (PI) was calculated as the following fatty acids ratio: 20:5 + 22:6 / 16:0 (Lubis and Buckle, 1990).

$\underline{\text { Fluorescence analysis }}$

A Perkin-Elmer LS 3B fluorescence spectrophotometer was used for fluorescence determination. The fluorescence shift $(\delta \mathrm{F})$ was calculated as follows:

$\mathrm{F} 3 / \mathrm{F} 3_{\mathrm{st}}$

$\delta \mathrm{F} \quad=$

$\mathrm{F} 1 / \mathrm{F} 1_{\mathrm{st}}$

where F3 and F1 are the fluorescence intensities of the sample at 393/463 nm and $327 / 415 \mathrm{~nm}$, respectively. $\mathrm{F} 3_{\text {st }}$ and $\mathrm{F} 1_{\text {st }}$ are the fluorescence intensities of a quinine sulfate solution $\left(1 \mu \mathrm{g} / \mathrm{ml}\right.$ in $\left.0.05 \mathrm{M} \mathrm{H}_{2} \mathrm{SO}_{4}\right)$ at the corresponding wavelength.

The fluorescence shift was studied on the aqueous $\left(\delta \mathrm{F}_{\mathrm{aq}}\right)$ and organic $\left(\delta \mathrm{F}_{\mathrm{or}}\right)$ phases resulting from lipid extraction (Bligh and Dyer, 1959) of white muscle and also on the liquid medium of the can (filling or packing medium) $\left(\delta \mathrm{F}_{\mathrm{pm}}\right)$.

For the fluorescence analysis of the packing media, the liquid part of the can was carefully drained off. In the case of the canned with oil samples, $1 \mathrm{~g}$ of each filling oil was made up to $15 \mathrm{ml}$ with chloroform. For the brine canned samples, the whole packing brine was made up to $100 \mathrm{ml}$ with aq. $2 \% \mathrm{NaCl}$. Both kinds of solutions were then directly employed for fluorescence analysis. 
Data resulting from basic analyses, lipid damage measurements and fluorescence shifts were subjected to the ANOVA one-way method, according to Sokal and Rohlf (1981). Regression models were assayed with all variables studied; linear and non linear correlations were carried out using the Statistica package (Statsoft, 1994). Significance was declared at $\mathrm{p}<0.05$.

\section{RESULTS}

\section{A) Chilled storage and brine canning}

\section{Basic and lipid damage determinations}

No differences in water content in canned sardines were obtained as a result of differences in chilling time (Table 1). Lipid contents in the canned material did not show clear effects resulting from the previous storage and few significant differences were observed (Table 1).

The common quality indexes related to lipids showed different tendencies relative to the time of storage. An increase in the FFA content after canning can be inferred by comparing the $\mathrm{RAW}_{\mathrm{CH}}$ and $\mathrm{BCS}_{0}$ samples $(0.20 \pm 0.05$ and $4.11 \pm 0.23$, respectively) (Table 2 and Figure 1.A.), according to the thermal physical breakdown of lipids in canned products (Medina et al., 1994). Regarding the time of previous chilled storage, a progressive increase in the FFA proportion of canned products was observed (Figure 1.A.). Data obtained showed a significant linear correlation with the time of storage, and subsequently with the quality of the starting material $(r=0.51)$.

The determination of the TBA reactive substances (TBARS) in the canned samples did not provide a clear tendency by comparison with the previous time of storage (Figure 1.B.). No significant linear and non linear correlations could be obtained 
between both parameters. A large difference was obtained in TBA values between RAW $_{\mathrm{CH}}$ and $\mathrm{BCS}_{0}$ samples (Table 2 and Figure 1.B.).

The PI value showed a decreasing tendency as long as the storage time increased (Figure 1.C.). However, no significant correlations could be obtained. By comparing the different canned values, no significant differences were obtained. Some previous research on cooking (Hearn et al., 1987; Gallardo et al., 1989) and canning (Hale and Brown, 1983; Aubourg et al., 1995a) has shown that the polyunsaturated fatty acids (PUFA) proportion in total lipids did not diminish as a result of such thermal processes.

\section{$\underline{\text { Fluorescence analysis }}$}

The fluorescence shift measured in the aqueous phase $\left(\delta \mathrm{F}_{\mathrm{aq}}\right)$ did not show a good relationship with the previous storage time (Figure 2.A.). Different storage times of the starting chilled material did not provide significant differences between the corresponding canned products. The best results were obtained by using an exponential model but the correlation calculated was poor $(r=0.24)$. An increase was observed resulting from the canning process (comparison of $\mathrm{RAW}_{\mathrm{CH}}$ and $\mathrm{BCS}_{0}$ samples; Table 2 and Figure 2.A.) according with data previously described (Aubourg et al., 1992b).

The analysis of the organic phase (lipid extract) showed a significant linear dependence of the $\delta F_{\text {or }}$ value of the canned samples with the previous storage time (Figure 2.B., $r=0.47$ ). By comparing with the RAW ${ }_{\mathrm{CH}}$ sample (Table 2), a significant increase in canned samples was only detected after 10 days of previous storage (BCS 10 , Figure 2.B.).

The most satisfactory results were obtained in the analysis of the fluorescence shift from the filling liquid $\left(\delta \mathrm{F}_{\mathrm{pm}}\right)$ (Figure 2.C.). A stronger dependence with the 
previous storage time than the other measurements was obtained. The best results were obtained using a non linear fitting $(r=0.90)$.

\section{B) Frozen storage and oil canning}

Basic and lipid damage determinations

By comparing the $\mathrm{RAW}_{\mathrm{FR}}$ and $\mathrm{OCS}_{0}$ samples, a loss in the water content is concluded as a result of the canning process (Table 1). However, the different frozen storage times did not provide significant differences in the water content in the canned samples.

Regarding the lipid content, little significant differences were observed (Table 1). Different storage times of the frozen material did not provide differences in the canned samples. An important loss of lipids from muscle was observed by comparing the raw material (RAW $\mathrm{FR}_{\text {) }}$ and most of the oil canned samples. This effect is probably due to the extraction carried out by the filling oil (Aubourg et al., 1990).

The FFA content of the canned samples did not show a clear tendency in comparison with the previous frozen storage time (Figure 3.A.). No significant correlations between both parameters could be obtained. Canned samples without previous frozen storage $\left(\mathrm{OCS}_{0}\right)$ showed a very low FFA level compared with the remaining canned ones.

Results obtained for the brine canned samples (Figure 1.A.) showed that the thermal treatment itself causes a great increase in the FFA content. However, in the case of oil canning, no increase was observed (comparison of RAW $\mathrm{FR}_{\text {and }} \mathrm{OCS}_{0}$ samples; Table 2 and Figure 3.A.), that could be explained as a result of the presence of the oil medium in the muscle and a partial extraction of lipid classes from the muscle into the oil (Aubourg et al., 1990). 
Results obtained for the TBA-i are shown in Figure 3.B. An increasing storage time of the starting material did not produce a constant increase throughout the experiment. Significant correlations obtained using exponential models were poor $(\mathrm{r}=$ $0.23)$.

$\underline{\text { Fluorescence analysis }}$

A significant correlation was found by comparing the fluorescence shift measured in the aqueous phase $\left(\delta \mathrm{F}_{\mathrm{aq}}\right)$ of the canned samples with the time of frozen storage using exponential regression models ( $r=0.49$; Figure 4.A.).

Best results were obtained in the case of measuring the fluorescence shift in the organic phase $\left(\delta \mathrm{F}_{\mathrm{or}}\right)$ of the canned muscle (Figure 4.B.). A significant linear correlation with the previous storage time was obtained $(\mathrm{r}=0.62)$. A high increase was observed as a result of canning (comparison of $\mathrm{RAW}_{\mathrm{FR}}$ and $\mathrm{OCS}_{0}$ samples; Table 2 and Figure 4.B.) according to previous results (Aubourg et al., 1992b). Among canned sardines, an important increase of $\delta F_{\text {or }}$ value was obtained after 4 months of frozen storage (Figure 4.B.).

Regarding the fluorescence shift measured in the packing oil $\left(\delta \mathrm{F}_{\mathrm{pm}}\right)$ a strong dependence with the time of previous storage was obtained (Figure 4.C.). Good regressions, linear and quadratic were found ( $r=0.85$ and $r=0.91$, respectively). A high increase in the fluorescence value of canned samples was obtained after 4 months of frozen storage (Figure 4.C.). Results using a multiple regression model with the three measurements of fluorescence $\left(\delta \mathrm{F}_{\mathrm{aq}}, \delta \mathrm{F}_{\mathrm{or}}\right.$ and $\left.\delta \mathrm{F}_{\mathrm{pm}}\right)$ did not improve the correlation obtained using only the $\delta \mathrm{F}_{\mathrm{pm}}$.

According to previous results (Aubourg et al., 1992b), no differences between the fluorescence measured in the initial oil $(\delta \mathrm{F}=0.92)$ and the oil that had been 
separately canned (blank, $\delta \mathrm{F}=0.94$ ) were observed. Both measurements did not differ from the packing oil corresponding to $\mathrm{OCS}_{0}$ sample (Figure 4.C.), but were significantly different compared to the filling oil from samples that had been stored 0.5 months $\left(\mathrm{OCS}_{0.5}\right.$, Figure 4.C.).

\section{DISCUSSION}

Many previous reports have proved that fish quality progressively decreases throughout the chilling (El Marrakchi et al., 1990; Bennour et al., 1991) and frozen (Shewfelt, 1981; Verma et al., 1995) storages. In both treatments, lipid changes have shown to play an important role as quality indexes during the quality loss (Hwang and Regenstein, 1993; Han and Liston, 1988).

In this work the common indexes of lipid degradation measured in canned sardines did not show good correlations with the previous time of storage of the raw material, so that quality differences in the final product were difficult to assess. As an explanation, degradation products that are susceptible to be measured in such indexes can either be distributed into different phases of the can (packing medium, exudate, fish muscle), be partially destroyed during the heat process, or interact with other constituents, so that the determination of such degradation compounds can not always afford an accurate method for the quality assessment.

Fluorescence detection of interaction compounds formed between damaged lipids and other biological constituents (aminated, mainly) of the muscle has provided some interesting results. Fluorescence analysis of muscle lipids extracts $\left(\delta \mathrm{F}_{\mathrm{aq}}\right.$ and $\left.\delta \mathrm{F}_{\mathrm{or}}\right)$ afforded poor results that could be explained by the presence in the can of a filling liquid (brine or oil). In a previous paper (Aubourg et al., 1997), good correlations were 
obtained between the chilled storage time and the $\delta \mathrm{F}_{\mathrm{aq}}$ and $\delta \mathrm{F}_{\text {or }}$ values in chilled sardine.

However, the analysis of both packing media in the present work showed a satisfactory correlation with the time of storage of the raw material employed for canning. Values obtained for the linear and non linear regressions were always higher than in the case of classical indexes related to lipid damages. This kind of measurement showed to remain valid in spite of the fact that a strong thermal treatment (cooking and sterilization) is included.

Results obtained in this work reinforce the role of fluorescence detection of interaction compounds as a tool for quality assessment. Further experiments (comparison of different storage conditions, comparison of different filling media, and so on) focused in the fluorescence detection in the filling medium during canning are still necessary in order to consolidate such a rapid and sensible measurement as an accurate method to be correlated with the quality of the starting material.

\section{ACKNOWLEDGEMENTS}

The authors thank Mr. Oscar Bellón and Mr. Marcos Trigo for technical assistance and the Xunta de Galicia for financial support (Project XUGA 402 01B93). 
Ackman, R. G. Concerns for utilization of marine lipids and oils. Food Technol. 1988, 42(5), 151-155.

Ackman, R. G. Fatty acids. In Marine biogenic lipids, fats and oils. Ackman, R., Ed.; CRC Press, Boca Raton, Fl, USA, 1989; Vol. 1, pp. 103-137.

Aubourg, S. P.; Medina, I.; Gallardo, J. M.; Pérez.-Martín, R. I. Efecto del enlatado en aceite y salmuera y su posterior almacenamiento sobre los lípidos de la bacoreta (Euthynnus alletteratus). Grasas y Aceites 1995a, 46, 77-84.

Aubourg, S. P.; Medina, I.; Pérez-Martín, R. I. A comparison between conventional and fluorescence detection methods of cooking-induced damage to tuna fish lipids. Z. Lebensm. Unters. Forsch. 1995b, 200, 252-255.

Aubourg, S. P.; Pérez-Martín, R. I.; Medina, I.; Gallardo, J. M. Fluorescence formation by interaction of albacore (Thunnus alalunga) muscle with acetaldehyde in a model system. J. Agric. Food Chem. 1992a, 40, 1805-1808.

Aubourg, S. P.; Pérez-Martín, R. I.; Medina, I.; Gallardo, J. M. Fluorescence formation during albacore (Thunnus alalunga) thermal processing. Z. Lebensm. Unters. Forsch. 1992b, 195, 332-335.

Aubourg, S. P.; Sotelo, C. G.; Gallardo, J. M. Changes in flesh lipids and fill oils of albacore (Thunnus alalunga) during canning and storage. J. Agric. Food Chem. 1990, 38, 809-812.

Aubourg, S. P.; Sotelo, C. G.; Gallardo, J. M. Quality assessment of sardines during storage by measurement of fluorescent compounds. J. Food Sci. 1997, 62, 000.

Bennour, M.; El Marrakchi, A.; Bouchriti, N.; Hamama, A.; El Ouadaa, M. Chemical and microbiological assessments of mackerel (Scomber scombrus) stored in ice. J. Food Protect. 1991, 54, 784, 789-792. 
Bligh, E. G.; Dyer, W. J. A rapid method of total extraction and purification. Can. J. Biochem. Physiol. 1959, 37, 911-917.

Bouzas, J.; Kamarei, A. R.; Karel, M. Effect of extraction procedures on fluorescent chromophores in milk. J. Food Sci. 1985, 50, 1515-1516.

Cheftel, J. C.; Cheftel, H. Introducción a la Biología y Tecnología de Alimentos. Editorial Acribia, Zaragoza, 1976.

El Marrakchi, A.; Bennour, M.; Bouchriti, N.; Hamama, A.; Tagafait, H. Sensory, chemical and microbiological assessments of Maroccan sardines (Sardina pilchardus) stored on ice. J. Food Protect. 1990, 53, 600-605.

Gallardo, J. M.; Aubourg, S. P.; Pérez-Martín, R. I. Lipid classes and their fatty acids at different loci of albacore (Thunnus alalunga): Effects of precooking. J. Agric. Food Chem. 1989, 37, 1060-1064.

Gardner, H. W. Lipid hydroperoxide reactivity with proteins and amino acids: A review. J. Agric. Food Chem. 1979, 27, 220-229.

Hale, M. B.; Brown, T. Fatty acids and lipid classes of three underutilized species and changes due to canning. Marine Fish. Rev. 1983, 45, 4-6.

Han, T.-J.; Liston, J.. Correlation between lipid peroxidation and phospholipid hydrolysis in frozen fish muscle. J. Food Sci. 1988, 53, 1917-1918.

Hearn, T. L.; Sgoutas, S. A.; Sgoutas, D. S.; Hearn, J. A. Polyunsaturated fatty acids and fat in fish flesh for selecting species for health benefits. J. Food Sci. 1987, 52, 1209-1211.

Herbes, S. E.; Allen, C. P. Lipid quantification of freshwater invertebrates: method modification for microquantification. Can. J. Fish. Aquat. Sci. 1983, 40, 13151317. 
Hidalgo, F. J.; Zamora, R.; Girón, J. Modificaciones producidas en las proteínas alimentarias por su interacción con lípidos peroxidados. III. Consecuencias nutricionales y toxicológicas. Grasas y Aceites 1992, 43, 97-100.

Hwang, K. T.; Regenstein, J. M. Characteristics of mackerel mince lipid hydrolysis. J. Food Sci. 1993, 58, 79-83.

Kim, R. S.; Labella, F. S. Comparison of analytical methods for monitoring autoxidation profiles of authentic lipids. J. Lipid Res. 1987, 28, 1110-1117.

Leake, L.; Karel, M. Nature of fluorescent compounds generated by exposure of protein to oxidizing lipids. J. Food Biochem. 1985, 9, 117-136.

Lepage, G.; Roy, C. C. Direct transesterification of all classes of lipids in a one step reaction. J. Lipid Res. 1986, 27, 114-120.

Lowry, R. R.; Tinsley, I. J. Rapid colorimetric determination of free fatty acids. $J$. Amer. Oil Chem. Soc. 1976, 53, 470-472.

Lubis, Z.; Buckle, K. A. Rancidity and lipid oxidation of dried-salted sardines. Int. J. Food Sci. Technol. 1990, 25, 295-303.

Maruf, F. W.; Ledward, D. A.; Neale, R. J.; Poulter, R. G. Chemical and nutritional quality of Indonesian dried-salted mackerel (Rastrelliger kanagurta). Int. J. Food Sci. Technol. 1990, 25, 66-77.

Medina, I.; Sacchi, R.; Aubourg, S. P. ${ }^{13}$ C-NMR monitoring of FFA release after fish thermal processing. J. Am. Oil Chem. Soc. 1994, 71, 479-482.

Melton, S. L. Methodology for following lipid oxidation in muscle foods. Food Technol. 1983, 37, 105-111, 116.

Nielsen, H. K.; Finot, P. A.; Hurrell, R. F. Reactions of proteins with oxidizing lipids. 1. Analytical measurements of lipid oxidation and of amino acid losses in a whey protein-methyl linolenate model system. British J. Nutrit. 1985, 53, 75-86. 
Pearson, A. M.; Love, J. D.; Shorland F. B. Warmed-over flavor in meat, poultry and fish. Adv. Food Res. 1977, 23, 2-61.

Pérez-Martín, R. I., Banga, J. R., Sotelo, C. G., Aubourg, S. P. and Gallardo, J. M. Prediction of precooking times for albacore (Thunnus alalunga) by computer simulation. J. Food Eng. 1989, 10, 83-95.

Pigott, G. M.; Tucker, B. W. Science opens new horizons for marine lipids in human nutrition. Food Rev. Int. 1987, 3, 105-138.

Pokorný, J. Browning from lipid-protein interactions. Prog. Food Nutrit. Sci. 1981, 5, 421-428.

Shewfelt, R. L. Fish muscle lipolysis- A review. J. Food Biochem. 1981, 5, 79-100.

Sokal, R. R.; Rohlf, F. J. Biometry. $2^{\text {nd }}$ edition. W. Freeman and Company, San Francisco, 1981.

Statsoft. Statistica for Macintosh; Statsift and its licensors: Tulsa, Oklahoma, 1994.

Verma, J. K.; Srikar, L. N.; Sudhakara, N. S.; Sarma, J. Effects of frozen storage on lipid frehness parameters and some functional properties of oil sardine (Sardinella longiceps) mince. Food Res. Internat. 1995, 8, 87-90.

Vyncke, W. Direct determination of the thiobarbituric acid value in trichloracetic acid extracts of fish as a measure of oxidative rancidity. Fette Seifen Anstrichm. 1970, 72, 1084-1087. 
TABLE 1

Basic analyses ${ }^{*}$ in brine canned sardine (BCS) ${ }^{* *}$ and oil canned sardine (OCS) $)^{* * *}$

\begin{tabular}{|c|c|c|c|c|c|}
\hline \multicolumn{3}{|c|}{ Brine Canned Sardine } & \multicolumn{3}{|c|}{ Oil Canned Sardine } \\
\hline & Water & Lipid & & Water & Lipid \\
\hline & Content & Content & & Content & Content \\
\hline RAW $_{\mathbf{C H}}$ & $69.02^{\mathrm{a}}$ & $3.69^{\mathrm{a}}$ & $\mathbf{R A W}_{\mathrm{FR}}$ & $68.20^{b}$ & $7.11^{c}$ \\
\hline $\mathbf{B C S}_{0}$ & $71.04^{\mathrm{a}}$ & $3.74^{\mathrm{a}}$ & $\mathrm{OCS}_{\mathbf{0}}$ & $59.87^{\mathrm{a}}$ & $3.99^{a}$ \\
\hline $\mathbf{B C S}_{2}$ & $67.95^{\mathrm{a}}$ & $4.07^{\mathrm{ab}}$ & $\mathrm{OCS}_{0.5}$ & $60.26^{a}$ & $4.23^{a b}$ \\
\hline $\mathrm{BCS}_{6}$ & $71.00^{\mathrm{a}}$ & $5.38 \mathrm{bcd}$ & $\mathbf{O C S}_{2}$ & $57.98^{a}$ & $4.42^{\mathrm{ab}}$ \\
\hline $\mathrm{BCS}_{10}$ & $68.84^{\mathrm{a}}$ & $5.99^{d}$ & $\mathrm{OCS}_{4}$ & $58.09^{a}$ & $3.63^{\mathrm{a}}$ \\
\hline $\mathrm{BCS}_{13}$ & $70.67^{\mathrm{a}}$ & $5.56^{\mathrm{cd}}$ & $\mathrm{OCS}_{8}$ & $60.08^{a}$ & $5.94^{b c}$ \\
\hline BCS $_{15}$ & $70.56^{\mathrm{a}}$ & $4.49^{\mathrm{abc}}$ & $\mathrm{OCS}_{12}$ & $59.02^{a}$ & $3.60^{\mathrm{a}}$ \\
\hline
\end{tabular}

* Mean values of three determinations. For each set of canned sardine, values in the same column followed by different letters are significantly different $(\mathrm{p}<0.05)$.

${ }^{* *}$ Sample names: $\mathrm{RAW}_{\mathrm{CH}}$ (raw sardine); $\mathrm{BCS}_{0}, \mathrm{BCS}_{2}, \mathrm{BCS}_{6}, \mathrm{BCS}_{10}, \mathrm{BCS}_{13}$ and $\mathrm{BCS}_{15}$ (canned sardine that was kept chilled during 0, 2, 6, 10, 13 and 15 days, respectively).

*** Sample names: RAW (canned sardine that was kept frozen during 0, 0.5, 2, 4, 8 and 12 months, respectively). 


\section{TABLE 2}

Measurements ${ }^{*}$ of lipid degradation for raw samples employed in both experiments ${ }^{* *}$.

\section{Brine Canned Sardine (RAW $\left.{ }_{\mathrm{CH}}\right) \quad$ Oil Canned Sardine $\left(\right.$ RAW $\left._{\mathrm{FR}}\right)$}

$\begin{array}{lll}\text { FFA } & 0.20 \pm 0.50 & 1.11 \pm 0.09\end{array}$

$\begin{array}{lll}\text { TBA-i } & 0.98 \pm 0.34 & 0.47 \pm 0.24\end{array}$

PI $\quad 1.66 \pm 0.04$

$\begin{array}{lll}\delta F_{\text {aq }} & 0.78 \pm 0.13 & 0.37 \pm 0.04\end{array}$

$\begin{array}{lll}\delta \mathbf{F}_{\text {or }} & 1.50 \pm 0.44 & 0.43 \pm 0.06\end{array}$

*FFA: free fatty acids, TBA-i: thiobarbituric acid index, PI: polyene index, $\delta \mathrm{F}_{\text {aq }}$ and $\delta \mathrm{F}_{\text {or }}$ fluorescence shifts of the aqueous and organic phases, respectively.

${ }^{* *}$ Mean values of three determinations \pm standard deviations. 


\section{FIGURES}

\section{Figure 1:}

Lipid damage measurements in brine canned sardine after chilled storage. A. FFA, B. TBA-i. and C. PI. Abbreviations as specified in Table 2.

\section{Figure 2:}

Fluorescence shifts in brine canned sardine after chilled storage. A. $\delta F_{\text {aq }}$, B. $\delta F_{\text {or }}$ and $\mathbf{C}$. $\delta \mathrm{F}_{\mathrm{pm}}$. Abbreviations as specified in Table $2 ; \delta \mathrm{F}_{\mathrm{pm}}$ : fluorescence shift of the packing medium.

\section{Figure 3:}

Lipid damage measurements in oil canned sardine after frozen storage. A. FFA and B. TBA-i. Abbreviations as specified in Table 2.

\section{Figure 4:}

Fluorescence shifts in oil canned sardine after frozen storage. $\mathbf{A} . \delta \mathrm{F}_{\mathrm{aq}}, \mathbf{B} . \delta \mathrm{F}_{\mathrm{or}}$. and $\mathbf{C}$. $\delta \mathrm{F}_{\mathrm{pm}}$. Abbreviations as specified in Table 2 and Figure 2. 